\title{
Factors related to rapidity of housing placement in Housing and Urban Development-Department of Veterans Affairs Supportive Housing program of 1990s
}

\author{
Jack Tsai, PhD; ${ }^{1-2 *}$ Maria O’Connell, PhD; ${ }^{2-3}$ Wesley J. Kasprow, PhD, MPH; ${ }^{4}$ Robert A. Rosenheck, MD ${ }^{1-2,5}$ \\ ${ }^{1}$ Department of Veterans Affairs (VA) Connecticut Healthcare System, West Haven, CT, and Department of Psychiatry, \\ Yale School of Medicine, New Haven, CT; ${ }^{2}$ VA National Center on Homelessness Among Veterans, West Haven, CT; \\ ${ }^{3}$ Yale Program for Recovery and Community Health, New Haven, CT; ${ }^{4}$ VA Northeast Program Evaluation Center, West \\ Haven, CT; ${ }^{5}$ Department of Epidemiology and Public Health, Yale School of Public Health, New Haven, CT, and VA \\ New England Mental Illness Research, Education, and Clinical Center, West Haven, CT
}

\begin{abstract}
The Housing and Urban Development-Department of Veterans Affairs Supportive Housing (HUD-VASH) program is the largest supported housing program in the country for homeless veterans who are seeking rapid entry into permanent independent housing. This study examined factors related to how rapidly clients were housed in the early years of the program and how long they stayed in the program. Mental health, substance abuse, work/income, criminal history, and site were examined as predictors of process times. Regression analyses based on 627 HUD-VASH clients who entered the program between 1992 and 2003 showed that client characteristics were not rate-limiting factors for obtaining HUD-VASH housing; i.e., clients who had greater substance abuse problems or more extensive criminal histories did not take longer to obtain housing. The large differences associated with site of entry partly reflected a curvilinear relationship between the duration of operation of the HUD-VASH program and process times; i.e., at relatively younger and older programs, clients entered housing slightly faster than at programs in the middle range. Lastly, HUD-VASH clients whose case managers reported good therapeutic alliances stayed in the program longer. These findings have implications for the continued expansion of the HUD-VASH program.
\end{abstract}

Key words: criminal history, homelessness, program development, program operation, severe mental illness, substance abuse, supported housing, therapeutic alliance, VA, veterans.

\section{INTRODUCTION}

A central goal of permanent supported housing programs is rapid exit from homelessness and prolonged program participation. Yet few studies have examined the actual length of time it takes for clients to be screened, admitted, and placed into independent housing or reported the duration of participation among those housed. Supported housing programs have different methods of providing clients with various services that may affect how fast clients enter community housing. Some programs have partnerships with housing providers that keep apartments available for clients [1], other programs own or hold the lease to apartments that they then rent to clients [2-3], while others provide rental subsidies and case management

Abbreviations: ASI = Addiction Severity Index, HUD-VASH = Housing and Urban Development-Department of Veterans Affairs Supportive Housing, SD = standard deviation, VA = Department of Veterans Affairs.

* Address all correspondence to Jack Tsai, PhD; Yale University-Psychiatry, 950 Campbell Ave, Bldg 36, West Haven, CT 06516; 203-932-5711, ext 2090; 203-933-3478.

Email: Jack.tsai@yale.edu

DOI:10.1682/JRRD.2010.09.0178 
assistance to help clients obtain community housing [4-5]. One of the largest supported housing programs in the United States is the Housing and Urban DevelopmentDepartment of Veterans Affairs Supportive Housing (HUD-VASH) program, which serves chronically homeless veterans with disabilities. HUD-VASH was originally implemented in 1992 and has provided thousands of veterans with Section 8 vouchers along with supportive case management services. Initially implemented at 19 Department of Veterans Affairs (VA) medical centers, HUDVASH has recently expanded dramatically and is now serving more than 20,000 veterans at 132 VA medical centers [6].

Timely housing entry, while desirable, can be challenging because clients must complete numerous processes before entering housing. These processes can be broken down into four stages: time from intake in the community to specific referral to HUD-VASH, time from referral to signed treatment contract, time from signed contract to receipt of voucher, and finally, time from receipt of voucher to moving into housing. In each of these processes, different factors may be involved in facilitating client progress. From intake to referral, the referring clinician may be central; from referral to signed treatment contract, the HUD-VASH case manager is central; from signed contract to receipt of voucher, both the HUD-VASH case manager and the public housing authority are involved; and from receipt of voucher to housed, the HUD-VASH case manager, the veteran, and landlords of prospective apartments are all extensively involved.

Only one previous study has examined the time it takes for clients in HUD-VASH or any other supported housing program to enter housing [7]. That study found that although HUD-VASH was intended to provide rapid access to independent housing, the actual progression through the various processes was apparently slow, taking several months, and many clients did not stay in the program for the full 5-year period of potential data collection. Administrative data from 2,925 HUD-VASH clients at 36 sites showed the average time from program entry to housing placement was 110 days and that clients remained in the program for an average of 2.6 years in a 5-year follow-up period. Regression analyses found that African-American clients took longer to enter housing after receiving a voucher, while clients who had a mental illness and comorbid substance use disorder obtained housing faster, but site accounted for the greatest proportion of variance in process times.
In the current study, we extend these findings [7] by combining administrative data with further clinical information available on a subset of program participants to examine factors beyond basic sociodemographic characteristics that may be related to the rapidity of placement and duration of participation. More specifically, measures of psychiatric and substance abuse symptoms, along with work and criminal histories, were examined as additional predictors of process times. We hypothesized that clients with more psychiatric and substance abuse symptoms and more extensive criminal histories would be more difficult to house and would accordingly have longer process times. Service delivery and therapeutic alliance measures were also examined as predictors of program tenure, with the hypothesis that clients who received more services and had stronger therapeutic alliances with their case managers over time would remain in the program longer. Finally, differences between sites were explored based on the population densities of the cities in which the sites were located, service variables at the site level, and the ages of the sites, i.e., how long programs had been in operation at the sites.

\section{METHODS}

\section{Program and Sample Description}

A national data set on HUD-VASH program participants who entered the program between 1992 and 2003, which was used in a previous study on HUD-VASH process times [7], was combined with a data set on a multisite randomized controlled trial of HUD-VASH and additional observational data collected during the early years of program operation [8]. We used data from the early years of the HUD-VASH program because they were complete and contained variables that have not been collected in more recent years. The combined data set contained data for a total of 627 participants from 22 sites, with $29.9 \pm 16.1$ participants per site (all data presented as mean \pm standard deviation [SD] unless otherwise noted).

Using data from the 2000 U.S. Census [9], we categorized sites by the population density of the cities in which the sites were located. Using 2,000 people/ $\mathrm{ft}^{2}$ as the dividing point, we categorized sites as being in either low- or high-population cities.

Eligibility criteria for HUD-VASH during the years 1992 to 2003 when these clients entered the program included being eligible for VA services, living in a shelter 
or on the street for at least 30 days, and having a psychiatric and/or substance use disorder at the time of initial contact. Veterans were referred to HUD-VASH by clinicians working in specialized VA homeless services programs, and once admitted into HUD-VASH, they were assigned a HUD-VASH case manager, most of whom were master's level social workers. Case managers assisted clients in obtaining Section 8 vouchers and locating and moving into apartments and provided intensive case management support. An intake assessment was administered by staff upon initial contact, entry and housing procurement forms were used through the various phases of HUD-VASH, and clinical interviews were conducted with clients at baseline and every 3 months.

\section{Measures}

Sociodemographic characteristics and mental health diagnoses of clients were obtained by clinical staff through interviews and reviews of existing medical records. Once participants were referred to HUD-VASH, clinical staff documented key dates of progression through the various phases of the housing procurement process. Key dates in the housing process included the date clients were referred to HUD-VASH, the date the treatment plan contract was signed, the date of the first visit to the public housing authority, and the date clients moved into an apartment.

Mental health and substance abuse status were assessed with items from the Addiction Severity Index (ASI) [10]. In the current study, 8 items about psychiatric symptoms, 6 items from the alcohol subscale, and 13 items from the drug subscale were used. The psychiatric items asked participants yes/no questions about whether they had experienced a variety of mental health symptoms in the last month. For the alcohol and drug subscales, items asked participants about the frequency and extent of their substance use in the last month. Items on the alcohol and drug subscales were combined for a standard composite score ranging from 0 to 1 , with higher scores reflecting more serious substance abuse problems.

Work and income were recorded by asking participants the number of days they worked in the past month. Income from employment, public support, and other sources was recorded, and the sum of these three sources was recorded as total income. Public support income included income from unemployment insurance, welfare, social security, disability, or pension. Other income included money from friends and family, panhandling, and illegal means.
Criminal history was obtained through 18 items from the ASI [10], which was designed to measure the severity of potential treatment problems in areas commonly affected by alcohol and drug dependence, including number of past convictions, length of prior incarceration, and current legal status. Types of criminal convictions were categorized as minor, major, or serious crime offenses.

Treatment relationships between staff and clients were measured through 10 items that clinical staff used to document their own activities supporting clients' recovery, including frequency of contacts and average length of contact. Clinicians also completed a five-item therapeutic alliance scale based on the Working Alliance Inventory [11] concerning their relationship with each of their clients. Both treatment relationship measures were averaged across all time periods for each client.

\section{Data Analysis}

Demographic and background variables of all participants were summarized with means, SDs, and frequency counts. To explore whether the population density of sites was a factor in process times, we conducted a repeated measures analysis of variance with a between-subjects factor. The repeated measures (within-subject factor) compared process times within each site region (high or low population density), and the between-subjects factor compared site regions across process times. Fisher's least significant difference method was used for post hoc comparisons.

To compare process times between sites with different total durations of operation, we subtracted the first date that the site began to issue vouchers from the date that the last client in the data set participated in the program across all sites (May 2003). The relationship between duration of site operation and process times was explored with a scatter plot and linear and nonlinear regression analysis.

We conducted multiple regression analysis to identify mental health, substance abuse, work, and criminal history at baseline as predictors of process times. Demographics (age, sex, race, education, and marital status), baseline residential status (whether client was in residential treatment or homeless at time of program entry), and site were entered into the first block (dummy variables were created for nominal variables) simultaneously; then mental health, substance abuse, work, and criminal history variables at baseline were entered into the second block using a stepwise method. To analyze predictors of length of program participation, we entered treatment 
relationship values in a stepwise method after demographics, baseline residential status, site, and all mental health and substance abuse symptoms.

\section{RESULTS}

Table 1 shows the demographics, mental health, substance abuse, income, and criminal history status of all participants at baseline. On average, the majority of participants were white males, in their 40s, not married, and had a high school education. Participants had been homeless an average of $2.4 \pm 1.3$ times in their lifetime and been homeless for a total of $3.6 \pm 4.1$ years. Most participants had a mental health or substance abuse diagnosis, few were employed, and many had a criminal history.

Table 2 shows the mean and standard deviation of the process times for participants housed in the HUD-VASH program by population density and for all participants. Participant averages were $117.3 \pm 136.9$ days from intake to referral, $43.2 \pm 77.2$ days from referral to signed treatment

Table 1.

Baseline characteristics and psychosocial status of all participants $(N=$ 463-627).

\begin{tabular}{lc}
\hline Sociodemographics and Diagnosis & Mean \pm SD or $\boldsymbol{n}(\mathbf{\%})$ \\
\hline Age & $43.0 \pm 8.2$ \\
Sex: Male & $595(95.0)$ \\
Race & \\
White & $244(38.9)$ \\
Black & $220(35.1)$ \\
Hispanic & $22(3.5)$ \\
Asian/Indian/Alaskan & $5(0.8)$ \\
Missing & $136(21.7)$ \\
Education (years) & $12.6 \pm 1.8$ \\
Married & $28(4.5)$ \\
Mental Health Diagnosis & $75(12.0)$ \\
Psychotic Disorder & $157(25.0)$ \\
Mood Disorder & $63(10.0)$ \\
Personality Disorder & $64(10.2)$ \\
Posttraumatic Stress Disorder & $124(19.8)$ \\
Adjustment Disorder/Other & $167(26.6)$ \\
No Diagnosis/Missing & \\
Substance Abuse Diagnosis & $288(45.9)$ \\
Alcohol Abuse/Dependency & $240(38.3)$ \\
Drug Abuse/Dependency & $155(24.7)$ \\
Dual Diagnosis (Mental Health and & \\
Substance Abuse Diagnosis) & \\
\hline
\end{tabular}

Table 1. (cont)

Baseline characteristics and psychosocial status of all participants $(N=$ 463-627).

Sociodemographics and Diagnosis

Mean \pm SD or $n(\%)$

Mental Health Status in Past Month:

Symptoms

Serious Depression

$179(28.5)$

Serious Anxiety/Tension

$213(34.0)$

Hallucination

$67(10.7)$

Cognitive Problem

187 (29.8)

Violent Behavior

$70(11.2)$

Suicidal Ideation

$57(9.1)$

Suicidal Attempt

$6(1.0)$

Taking Medication

237 (37.9)

Substance Abuse Status in Past Month

Days Intoxicated

$4.1 \pm 8.7$

Money Spent on Alcohol (\$)

Used Drugs

$51.81 \pm 165.40$

$147(23.4)$

Money Spent on Drugs (\$)

ASI-Alcohol Use

$111.43 \pm 456.78$

$0.2(0.2)$

$0.1(0.1)$

Work and Income in Past Month

Days Worked

$4.2 \pm 7.5$

Employment Income (\$)

$127.80 \pm 282.2$

Public Support Income (\$)

$231.80 \pm 319.50$

Other Sources of Income (\$)

$47.80 \pm 250.80$

Criminal History

Lifetime Incarceration (months)

$9.8 \pm 20.3$

Number of Convictions

$2.0 \pm 3.2$

Last Conviction: Minor Crime Shoplifting/Vandalism

18 (2.9)

Disorderly Conduct

42 (9.9)

22 (3.5)

83 (13.2)

Driving While Intoxicated

$30(4.8)$

Parole/Probation Violation

$9(1.4)$

Last Conviction: Major Crime

Drug Charge

$55(8.8)$

Weapons Offense

$11(1.8)$

Burglary/Larceny

$25(4.0)$

Assault

37 (5.9)

Last Conviction: Serious Crime

Arson

$1(0.2)$

Robbery

$14(2.2)$

Rape

$2(0.3)$

$5(0.8)$

Homicide/Manslaughter

$4.3 \pm 11.3$

$15(2.4)$ 
Table 2.

Process times participants spent in Housing and Urban Development-Department of Veterans Affairs Supportive Housing by population density and at all sites.

\begin{tabular}{lcccccccc}
\hline \multicolumn{1}{c}{ Site } & $\begin{array}{c}\text { 1. Intake to } \\
\text { Referral (d) }\end{array}$ & $\begin{array}{c}\text { 2. Referral to } \\
\text { Signed } \\
\text { Contract (d) }\end{array}$ & $\begin{array}{c}\text { 3. Signed } \\
\text { Contract to } \\
\text { Voucher (d) }\end{array}$ & $\begin{array}{c}\text { 4. Voucher to } \\
\text { Housed (d) }\end{array}$ & $\begin{array}{c}\text { Total from } \\
\text { Intake to } \\
\text { Housed (d) }\end{array}$ & $\begin{array}{c}\text { Housed to } \\
\text { Program } \\
\text { Termination (d) }\end{array}$ & $\begin{array}{c}\text { Test of Process } \\
\text { Times Within } \\
\text { Regions }\end{array}$ & $\begin{array}{c}\text { Test of Process } \\
\text { Times Between } \\
\text { Regions }\end{array}$ \\
\hline $\begin{array}{l}\text { Low Population Density } \\
\text { Cities }(n=52-102)\end{array}$ & $111.2 \pm 131.7$ & $17.9 \pm 43.5$ & $42.1 \pm 41.7$ & $30.9 \pm 38.9$ & $211.2 \pm 120.1$ & $883.4 \pm 606.1$ & $F(3,1098)=21.57^{\dagger}$ & $F(1,366)=1.10$ \\
$\begin{array}{l}\text { High Population Density } \\
\text { Cities }(n=525)\end{array}$ & $118.0 \pm 137.6$ & $47.7 \pm 81.0$ & $36.6 \pm 51.3$ & $48.7 \pm 47.0$ & $243.7 \pm 162.7$ & $1,077.3 \pm 586.0$ & - & - \\
$\begin{array}{l}\text { All Sites }(n=627) \\
\end{array}$ & $117.3 \pm 136.9$ & $43.2 \pm 77.2$ & $37.5 \pm 50.0$ & $46.2 \pm 46.3$ & $241.1 \pm 159.9$ & $1,047.8 \pm 592.7$ & $\begin{array}{l}F(3,1101)=73.85 ; \\
1>4>2,3^{\ddagger}\end{array}$ & NA \\
& & & & & & & &
\end{tabular}

*Repeated measures analysis of variance was only conducted on four numbered process times.

${ }^{\dagger} p<0.001$.

${ }^{\ddagger}$ Post hoc analyses showed process 1 took longer than process 4, which took longer than processes 2 and 3 .

NA = not applicable.

contract, $37.5 \pm 50.0$ days from signed treatment contract to receipt of voucher, $46.2 \pm 46.3$ days from receipt of voucher to housed; and 1,047.8 \pm 592.7 days from housed to program termination, showing substantial individual variation between participants. This variation was also substantial when averaged across participants within each site, with site averages ranging broadly from 32 to 1,024 days from intake to referral, 6 to 122 days from referral to signed treatment contract, 12 to 75 days from signed treatment contract to receipt of voucher, 4 to 98 days from receipt of voucher to housed, 118 to 1,101 days from intake to housed, and 362 to 1,732 days from housed to program termination. Across all sites, the slowest processing time was from intake to referral and the relatively fastest processing time was from signed treatment contract to receipt of voucher. No significant differences were noted in process times between sites in high versus low population density cities; however, an analysis of variance found that high population density sites had clients who had more days from housed to program termination, $F(1,539)=7.53, p<0.01$.

A scatter plot between the duration of site operation and average process time from intake to housed showed a nonlinear relationship. Two outliers were deleted (process times $=1,339$ days and 2,737 days) before a quadratic regression was fitted to the data (Figure). The quadratic regression $\left(b_{1}=28.49, b_{2}=-0.00\right)$ explained 9 percent of the variance in process time from intake to housed, whereas a linear regression $\left(b_{1}=-0.33\right)$ only explained 3 percent and a fitted cubic regression did not explain any additional variance. Thus, a slight pattern was found showing sites at the younger and older ranges of operation time tended to have faster processing times and sites in the middle tended to have slower processing times. When this relationship was examined at the individual

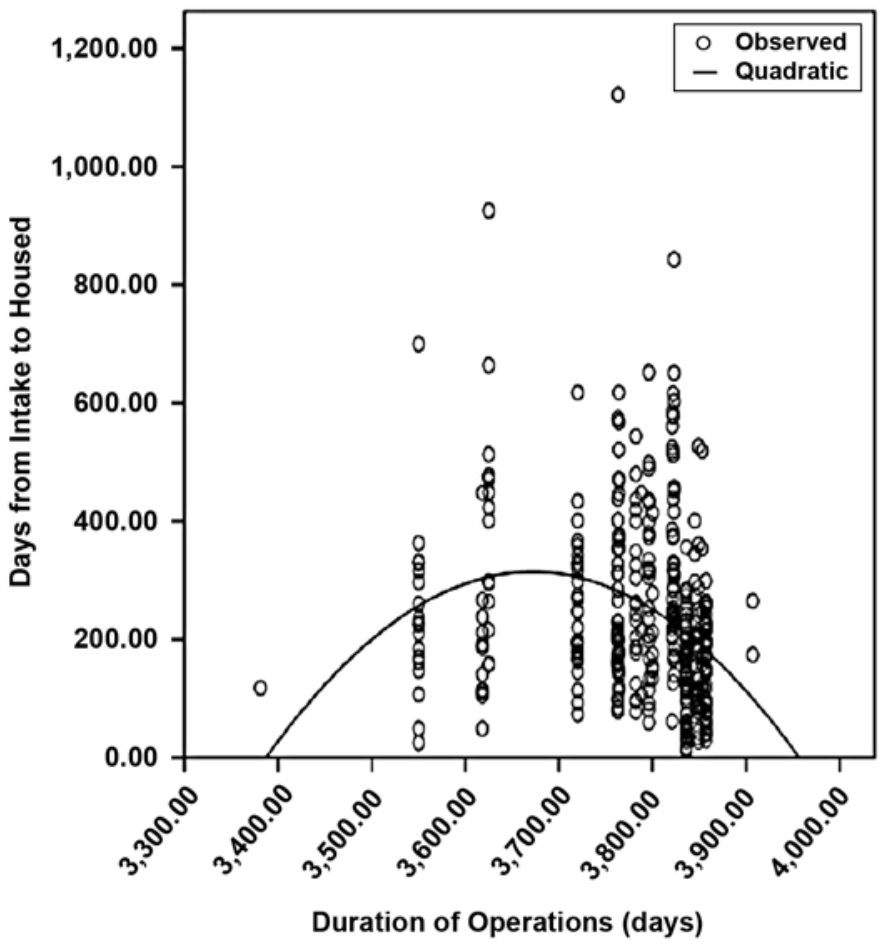

Figure.

Quadratic regression between duration of site operation and time from intake to housed.

client level (i.e., relationship between when clients entered the program and the time it took from intake to housed), no such pattern was found, suggesting this was a site-level phenomenon.

Table 3 shows the stepwise regression of mental health, substance abuse, work/income, and criminal history variables at baseline on process times after controlling for 
JRRD, Volume 48, Number 7, 2011

Table 3.

Stepwise regression using all mental health, substance abuse, work/income, and criminal history variables as predictors of process times. ${ }^{*}$

\begin{tabular}{|c|c|c|c|c|c|}
\hline Variable & $\begin{array}{l}\text { 1. Days from } \\
\text { Intake to } \\
\text { Referral }\end{array}$ & $\begin{array}{l}\text { 2. Days from } \\
\text { Referral to } \\
\text { Signed Contract }\end{array}$ & $\begin{array}{l}\text { 3. Days from } \\
\text { Signed Contract } \\
\text { to Receipt of } \\
\text { Voucher }\end{array}$ & $\begin{array}{l}\text { 4. Days from } \\
\text { Voucher to } \\
\text { Housed }\end{array}$ & $\begin{array}{c}\text { Total Days } \\
\text { from Intake } \\
\text { to Housed }\end{array}$ \\
\hline \multicolumn{6}{|l|}{ Mental Health Symptoms } \\
\hline Serious Anxiety/Tension & NS & NS & NS & $-0.19^{\dagger}$ & NS \\
\hline Hallucinations & $-0.21^{\dagger}$ & NS & NS & NS & NS \\
\hline \multicolumn{6}{|l|}{ Substance Abuse Symptoms: } \\
\hline Money Spent on Alcohol & NS & $0.17^{\dagger}$ & NS & NS & NS \\
\hline \multicolumn{6}{|l|}{ Work and Income } \\
\hline Employment Income & NS & $0.48^{\ddagger}$ & NS & NS & NS \\
\hline Days Worked for Pay & NS & $-0.37^{\S}$ & NS & NS & NS \\
\hline Public Support Income & NS & NS & NS & NS & $-0.21^{\dagger}$ \\
\hline \multicolumn{6}{|l|}{ Criminal History } \\
\hline Number of Criminal Convictions & NA & $0.23^{\S}$ & NA & NA & NA \\
\hline Last Conviction: Serious Crime & NA & NA & NA & NA & NA \\
\hline$R^{2}$ Change & $0.03^{\dagger}$ & $0.13^{\ddagger}$ & 0.00 & $0.03^{\ddagger}$ & $0.03^{\dagger}$ \\
\hline $\begin{array}{l}{ }^{*} \text { Demographics, baseline residential status, an } \\
\text { predictors are shown. } \\
{ }^{\dagger} p<0.05 . \\
{ }^{f} p<0.001 . \\
{ }^{p} p<0.01 . \\
\text { NA = not applicable, NS = not significant. }\end{array}$ & entered & before men & & n second & \\
\hline
\end{tabular}

demographics, residential status at baseline, and site. Only significant predictors are shown, and no common significant predictors across all stages of the housing entry process were found. For the first stage, participants who endorsed hallucinations tended to have fewer days from intake to referral. For the second stage, participants who spent more money on alcohol, had higher employment income, worked less days for pay, and had a greater number of criminal convictions had more days from referral to signed treatment plan contract. No significant predictors were found for the third process, from signed treatment contract to receipt of voucher. For the fourth stage, participants who endorsed serious anxiety/tension tended to have fewer days from receipt of voucher to housed. Overall, across stages, veterans who had higher public support income tended to have more rapid entry into housing. A stepwise regression of treatment relationship variables averaged over time found that after controlling for client demographics, baseline residential status, site, and mental health and substance abuse symptoms, the only significant predictor of participants' length of time in the HUD-VASH program was the therapeutic alliance ( $\beta=0.31, t=4.61, p<$ $0.001)$, which explained 8 percent of the variance. No other treatment relationship variables were significant predictors of program tenure.

\section{DISCUSSION}

This study examined the relationship between diverse veteran and service factors, how quickly clients were housed in the early years of the HUD-VASH program, and how long clients stayed in the program. First, clients' mental health, substance abuse, work/income, and criminal history explained little of the variance in process time from intake to housed. Thus, client characteristics were not a rate-determining factor in HUD-VASH process times; i.e., clients who had greater substance abuse problems or more extensive criminal histories did not take longer to obtain housing.

Second, large differences were found in process times between sites. This was not due to differences in the population densities where the sites were located but was partially due to differences in how long the sites had operated the HUD-VASH program. Our analysis revealed that a curvilinear relationship may exist between the 
duration of HUD-VASH program operation and process times; relatively younger and older programs processed clients slightly faster than programs in the middle range. However, a fine distinction was noted between young and old programs, and much of the variance in process times across program sites remains unexplained. Future research is needed on whether this difference still exists in more recent HUD-VASH programs, whether programs experience a learning curve in processing clients, and what other factors account for site differences.

One of the main findings of this study was that HUDVASH case managers who had good therapeutic alliances with their clients over time had clients who stayed in the program longer. This finding is consistent with the vast literature on the importance of therapeutic relationships [12-13] and underscores their importance in HUDVASH case management. We did not have adequate data to examine whether clients who did not have good therapeutic relationships also left the program for negative reasons. More research is needed on clients who leave the HUD-VASH program and how services are related to program termination.

Several other findings demonstrate a need for further research. Although client characteristics explained little variance in process times overall, they did account for a considerable amount (13\%) of variance in the process time from referral to signed treatment contract. Criminal history, employment income, number of days worked, and money spent on alcohol arose as predictors. Research is needed to better explain why client characteristics are particularly influential for clients signing treatment contracts after they are referred. Across sites, the longest process time in HUD-VASH was from intake to referral. This was likely due to the fact that some clients entered residential treatment after intake and did not receive a referral until after they were discharged or near discharge. Further research is needed on how best to coordinate these referrals. Whether a stay in residential treatment is even necessary is controversial [14-15], and while this has been the subject of several studies [16-18], the issue has not been resolved.

Importantly, this study was based on data collected on the HUD-VASH program of the 1990s; replication is needed to determine whether our results generalize to the HUD-VASH program of the 21st century. This study was also limited by the available data and measures that were used. Some crucial factors may not have been captured or measured. Anecdotally, we know that searching for apart- ments and obtaining money for security deposits for apartments can be large barriers for HUD-VASH clients. However, we did not have data to examine these factors. There may also have been mediating factors that we did not analyze. For example, therapeutic alliance may have been a mediator between the factors we examined (mental health and substance abuse symptoms, work and income, criminal history) and obtaining housing.

Some client characteristics, such as psychiatric symptoms, may have needed more extensive measures to accurately determine whether they were predictive of process times. Finally, our study was not able to examine the various possible sources of delays in process times. Because HUD-VASH involves multiple entities, delays could have culminated from a number of sources, including HUDVASH staff, other VA clinicians, the public housing authority processes and personnel, landlords, and the clients themselves. Nevertheless, this study contributes to the sparse literature on time issues in supported housing programs and has implications for program development and improvement.

\section{CONCLUSIONS}

Although entry into HUD-VASH housing during the 1990s was apparently slow, clients' mental health, substance abuse, work/income, and criminal history were not rate-determining factors. Variability was found in process times between sites, which can partially be attributed to how long the program had been operating. Once clients were in the program, those who had a good treatment relationship with their case manager stayed in the program longer.

\section{ACKNOWLEDGMENTS}

\section{Author Contributions:}

Data analysis: J. Tsai, M. O’Connell, R. A. Rosenheck.

Data collection: W. J. Kasprow, R. A. Rosenheck.

Drafting of manuscript: J. Tsai, M. O’Connell, R. A. Rosenheck.

Financial Disclosures: The authors have declared that no competing interests exist.

Funding/Support: This material was based upon work supported with resources from the VA, Veterans Health Administration, Office of Research and Development.

Disclaimer: The views presented here are those of the authors alone and do not represent the position of any Federal agency or of the U.S. Government. 


\section{REFERENCES}

1. Tsai J, Salyers MP, Rollins AL, McKasson M, Litmer ML. Integrated dual disorders treatment. J Commun Psychol. 2009;37(6):781-88.

2. McGraw SA, Larson MJ, Foster SE, Kresky-Wolff M, Botelho EM, Elstad EA, Stefancic A, Tsemberis S. Adopting best practices: Lessons learned in the Collaborative Initiative to Help End Chronic Homelessness (CICH). J Behav Health Serv Res. 2010;37(2):197-212. [PMID: 19644759] DOI:10.1007/s11414-009-9173-3

3. Mares AS, Rosenheck RA. HUD/HHS/VA collaborative initiative to help end chronic homelessness. West Haven (CT): VA Northeast Program Evaluation Center; 2009.

4. Hurlburt MS, Hough RL, Wood PA. Effects of substance abuse on housing stability of homeless mentally ill persons in supported housing. Psychiatr Serv. 1996;47(7):731-36. [PMID: 8807687]

5. Fosburg LB, Locke G, Peck L, Finkel M. National evaluation of the Shelter Plus Care Program: Final report. Washington (DC): United States Department of Housing and Urban Development, Office of Policy Development and Research; 1997.

6. Kasprow WJ, Rosenheck RA, Dilella D, Cavallaro L, Harelik N. Health care for homeless veterans programs: Twenty-second annual report. West Haven (CT): VA Northeast Program Evaluation Center; 2009.

7. O’Connell M, Kasprow W, Rosenheck RA. National dissemination of supported housing in the VA: Model adherence versus model modification. Psychiatr Rehabil J. 2010;33(4): 308-19. [PMID: 20374989]

DOI:10.2975/33.4.2010.308.319

8. Rosenheck R, Kasprow W, Frisman L, Liu-Mares W. Costeffectiveness of supported housing for homeless persons with mental illness. Arch Gen Psychiatry. 2003;60(9):940-51.

[PMID: 12963676]

DOI:10.1001/archpsyc.60.9.940

9. United States Census 2000 [Internet]. Washington (DC): United States Census; 2000. Available from: http://www.census.gov/main/www/cen2000.html

10. McLellan AT, Luborsky L, Woody GE, O’Brien CP. An improved diagnostic evaluation instrument for substance abuse patients: The Addiction Severity Index. J Nerv Ment Dis. 1980;168(1):26-33. [PMID: 7351540] DOI:10.1097/00005053-198001000-00006

11. Horvath AO, Greenberg LS. Development and validation of the Working Alliance Inventory. J Counseling Psychol. 1989;36(2):223-33. DOI:10.1037/0022-0167.36.2.223
12. Luborsky L, Rosenthal R, Diguer L, Andrusyna TP, Berman JS, Levitt JT, Seligman DA, Krause ED. The Dodo bird verdict is alive and well-mostly. Clin Psychol. 2002; 9(1):2-12.

13. Rosenzweig S. Some implicit common factors in diverse methods of psychotherapy. Am J Orthopsychiatry. 1936; 6(3):412-15. DOI:10.1111/j.1939-0025.1936.tb05248.x

14. Kertesz SG, Crouch K, Milby JB, Cusimano RE, Schumacher JE. Housing first for homeless persons with active addiction: Are we overreaching? Milbank Q. 2009;87(2): 495-534. [PMID: 19523126] DOI:10.1111/j.1468-0009.2009.00565.x

15. Tsemberis S. From streets to homes: An innovative approach to supported housing for homeless adults with psychiatric disabilities. J Community Psychol. 1999;27(2):225-41. DOI:10.1002/(SICI)1520-6629(199903)27:2<225::AIDJCOP9>3.0.CO;2-Y

16. Tsai J, Mares AS, Rosenheck RA. A multisite comparison of supported housing for chronically homeless adults: "Housing first" versus "residential treatment first.” Psychol Serv. 2010;7(4):219-32. DOI:10.1037/a0020460

17. O’Connell MJ, Kasprow W, Rosenheck RA. Direct placement versus multistage models of supported housing in a population of veterans who are homeless. Psychol Serv. 2009;6(3):190-201. DOI:10.1037/a0014921

18. Mares AS, Kasprow WJ, Rosenheck RA. Outcomes of supported housing for homeless veterans with psychiatric and substance abuse problems. Ment Health Serv Res. 2004;6(4): 199-211. DOI:10.1023/B:MHSR.0000044746.47589.06

Submitted for publication September 9, 2010. Accepted in revised form January 31, 2011.

This article and any supplementary material should be cited as follows:

Tsai J, O’Connell M, Kasprow WJ, Rosenheck RA. Factors related to rapidity of housing placement in Housing and Urban Development-Department of Veterans Affairs Supportive Housing program of 1990s. J Rehabil Res Dev. 2011;48(7):755-62.

DOI:10.1682/JRRD.2010.09.0178

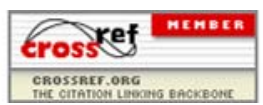

